\title{
LOCALISATION RARE DE L'HYPODERMA BOVIS CHEZ L'HOMME
}

\section{Par RIBEIRO DOS SANTOS}

Un malade, A. S., 42 ans, métis, Brésilien, agriculteur, habite une propriété rurale. Ses fonctions consistent à surveiller et contrôler les plantations et les récoltes des produits agricoles. Le soir, en ren-

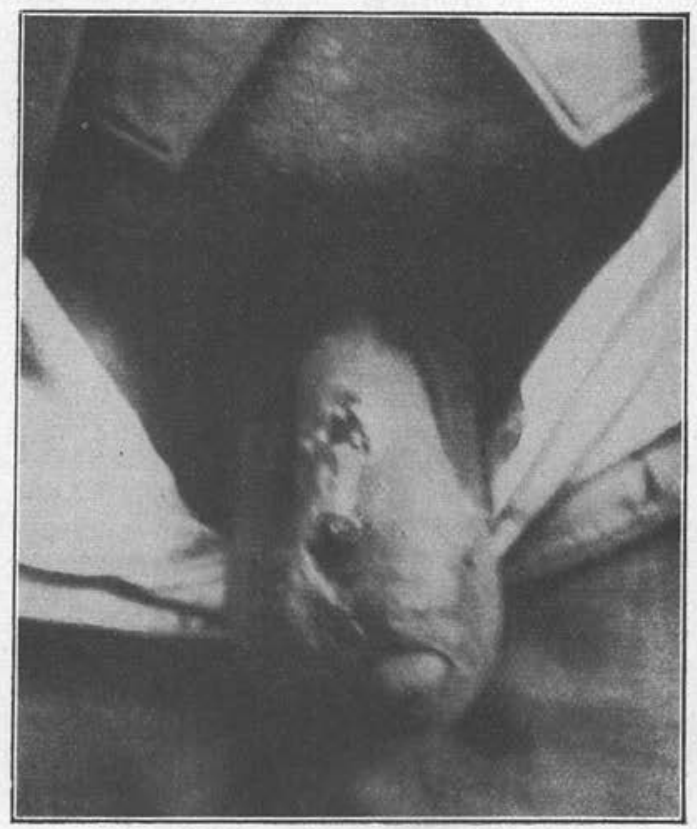

Fig. 1. - Aspect du pénis avec les deux nodules sur la partie dorsale.

trant de son travail, il se repose au bord d'un ruisseau, se couchant complètement nu dans l'herbe et parfois s'endormant ainsi. A son réveil, il se baigne et rentre. Un jour, il remarque sur le dos de son pénis deux nodules qui s'agrandissaient lentement et étaient dou-

Annales de Parasitologie, $\mathrm{T}$. IX, $\mathrm{x}^{\circ} 6 .-1^{\mathrm{e}}$ novembre 1931 , p. 512-513. 
loureux à la pression. Quoique connaissant, tant chez l'homme que chez les animaux, les lésions causées par l'hypoderme, il croit que ses lésions sont d'origine vénérienne, les attribuant à son dernier coït, datant de 8 jours, et, pour ce motif, vient nous consulter au dispensaire antivénérien.

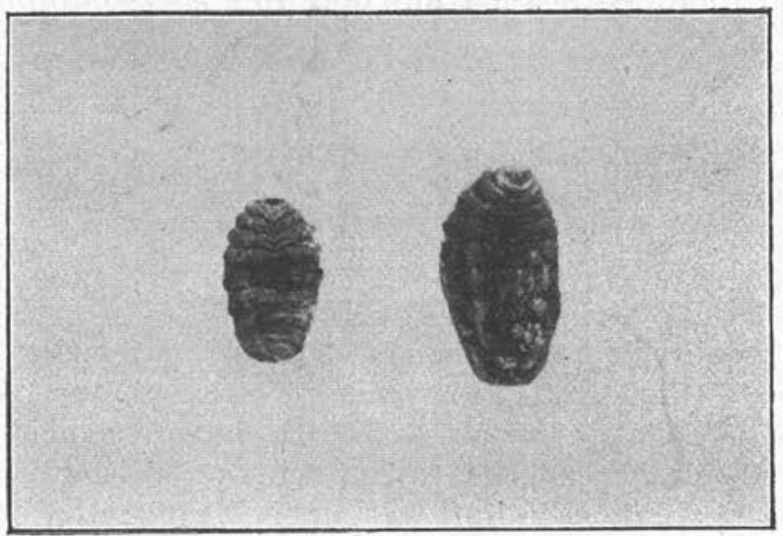

Fic. - Les deux larves d'Hypoderma bovis extraites des nodules.

En ourrant les deux nodules, nous retirons deux larves, une grande et une plus petite. Une tentative pour faire évoluer les deux larves dans une chambre spéciale n'a pas réussi, car elles sont mortes au bout de quelques heures, probablement à la suite des traumatismes causés par le patient, qui grattait les nodules prurigineux.

Nous avons eu l'occasion de présenter le cas aux Professeurs Pirajá da Silva et Flariano Silva.

Bahia, Brésil. 